\title{
Regulation of the anti-inflammatory cytokines interleukin-4 and interleukin-10 during pregnancy
}

\section{Piyali Chatterjee ${ }^{1,2}$, Valorie L. Chiasson ${ }^{1}$, Kelsey R. Bounds ${ }^{1}$ and Brett M. Mitchell ${ }^{1,2 *}$}

1 Department of Internal Medicine, Texas A\&M Health Science Center, Temple, TX, USA

2 Baylor Scott and White Health, Temple, TX, USA

\section{Edited by:}

Sinuhe Hahn, University Clinics Basel, Switzerland

Reviewed by:

Anne Schumacher, Experimental Obstetrics and Gynecology, Germany

Anurag Gupta, University of Zurich,

Switzerland

\section{*Correspondence:}

Brett M. Mitchell, Department of Internal Medicine, Texas A\&M Health Science Center, Baylor Scott and White Health, 702 SW HK Dodgen Loop, Temple, TX 76504, USA

e-mail: bmitchell@tamhsc.edu
Inflammation mediated by both innate and adaptive immune cells is necessary for several important processes during pregnancy. Pro-inflammatory immune cell activation plays a critical role in embryo implantation, placentation, and parturition; however dysregulation of these cells can lead to detrimental pregnancy outcomes including spontaneous abortion, fetal growth restriction, maternal pathology including hypertensive disorders, or fetal and maternal death. The resolution of inflammation plays an important role throughout pregnancy and is largely mediated by immune cells that produce interleukin (IL)-4 and IL-10. The temporal and spatial aspects of reducing inflammation during pregnancy represent a complex process that if not functioning optimally can lead to persistent inflammation and pregnancy complications. In this review, we examine how immune cells that produce IL-4 and IL-10 are regulated throughout pregnancy as well as the effects that reduced IL-4 and IL-10 signaling has on fetal and maternal physiology.

Keywords: inflammation, pro-inflammatory cytokines, anti-inflammatory cytokines, pregnancy disorders, immune cells

\section{INTRODUCTION}

The immunological features of normal pregnancy are unique as the maternal immune system has to accept a semi-allogeneic fetus, a product of two histo-incompatible individuals. Medawar proposed that in order to accept a half-foreign fetus, the mother needs to be in an immunosuppressed state (1). Recent progress in our understanding suggests that the maternal immune system not only needs to be suppressed but at the same time also needs to protect the mother and the growing fetus from infection during pregnancy. Thus, a successful pregnancy depends on the ability of the mother's immune system to become tolerant to paternal antigens as well as the ability to reject the fetus in case of pathogen infection.

The maternal immune response is regulated by a complex array of cytokines to protect the conceptus and promote proper growth and development of the placenta. Wegmann and colleagues suggested that during pregnancy there is a T-helper (Th) 2 bias to promote tolerance to the half-foreign fetus and Th1 cytokines are detrimental to the tolerance of the conceptus, similar to allografts in transplant recipients (2-5). It has been found that during tolerance induction to an allograft there is a decrease in Th1 cytokines such as interleukin (IL)-2 and IFN $\gamma$ and an increase in Th2 cytokines including IL-4 and IL-10. Conversely, high levels of IL-2 and IFN $\gamma$ were detected in rejecting allografts (6-8). Existing data suggest that Th2 bias in pregnancy is an oversimplified model and that during the various stages of pregnancy the pro-inflammatory and anti-inflammatory cytokine milieu is dynamically modulated. The first stage of pregnancy, which involves a blastocyst implanting into the uterus, is a predominantly pro-inflammatory phase. Localized activation of inflammatory mediators occurs and the mother's immune system repairs the damage done by the invading blastocyst. The second phase of pregnancy is a predominantly anti-inflammatory phase. Th2 cytokine skewing during the second phase of pregnancy can be systemic or local at the feto-maternal interface. The last phase of pregnancy is parturition, which causes contraction of the uterus and again, the pro-inflammatory milieu is predominant. Inflammation is tightly controlled during all stages of pregnancy, however excessive and persistent maternal inflammatory responses are associated with adverse pregnancy outcomes.

Pregnancy disorders such as preterm birth (PTB), fetal growth restriction (FGR), and preeclampsia (PE) are often associated with infection during pregnancy (9-11). Infection due to bacteria, viruses, and parasites, which normally induce a Th1 immune response can impact placental development and function and ultimately fetal survival (12). Th1 responses induce IFN $\gamma$ that in turn propagates Th1 responses by up-regulating IL-12 receptor expression and inhibiting Th2 responses.

Preterm birth is associated with increased production of proinflammatory cytokines and chemokines such as IL-1 $\beta$, IL-6, $\mathrm{TNF} \alpha$, and CXCL8 (13). These cytokines induce prostaglandin synthesis in the placental tissues that triggers preterm labor (14, 15). Likewise, maternal inflammation due to infection is an important contributor to the development of FGR (16). Administration of the anti-inflammatory cytokine IL-10 can attenuate FGR induced in rats by lipopolysaccharide (LPS) or infection with E. coli (17). The addition of exogenous IL-10 reduces fetal resorption in pregnancies of $\mathrm{CBA} / \mathrm{J} \times \mathrm{DBA} / 2$ mice. Anti-IL-10 neutralizing antibodies increase fetal loss and lead to growth defects after birth (18, 19). $\mathrm{PE}$ is also associated with an exaggerated maternal inflammatory response. Zenclussen and colleagues demonstrated that adoptive transfer of the Thl cells into pregnant mice was associated with the development of PE-like symptoms (20). Pro-inflammatory 
cytokines are not only increased in PE but the production of the anti-inflammatory cytokines IL-4 and IL-10 are also known to be decreased. In this review, we highlight how immune cells that produce IL- 4 and IL-10 are modulated during pregnancy and their role in adverse pregnancy outcomes.

\section{IMMUNE CELLS THAT PRODUCE IL-4 AND IL-10 AND THEIR ACTIONS}

Interleukin-4 and IL-10 are pleiotropic anti-inflammatory cytokines that function mainly by suppressing the proinflammatory milieu. Several different immune cells that produce IL-4 are activated T cells, mast cells, basophils, eosinophils, and NKT cells $(21,22)$. IL-4 aids in the polarization of antigenstimulated naïve Th cells into Th2 effector cells as well as propagates Th2 responses by binding to its receptor, IL- $4 \mathrm{R} \alpha$, and activating the signal transducer and activator of transcription (STAT) six signaling pathway (23-26). STAT6, through the induction of a zinc-finger transcription factor GATA3 (GATA-binding protein 3), might directly suppress Th1 cell development by silencing IFN $\gamma$ expression (27). Recent studies also indicate that IL-4 enhances Th2 immunity by inhibiting Th1 responses through the repression of IL-12 signaling (28). Several studies implicate a role for IL-4 in regulatory $\mathrm{T}$ cell (Treg) development and maintenance IL-4 signaling through STAT6 is important for FoxP3 mRNA expression and protein production in natural Tregs (29-32). IL-4 also induces the formation of inducible Tregs from naïve CD4+ T cells. Thus, IL-4 not only mediates Th2 cell function but also plays a part in the regulation of Tregs which play an important role in successful pregnancies.

Interleukin-10 production was first determined in Th2 cells and was initially thought to be only produced by immune cells, but later studies demonstrated that IL-10 is also produced by non-immune cells (33). Immune cells that produce IL-10 include subsets of T cells such as Th1, Th2, and Th17, as well as monocytes, macrophages, dendritic cells, human B cells, granulocytes, eosinophils, and mast cells. Non-immune cells that produce IL10 include keratinocytes, epithelial cells, and tumor cells. IL-10 primarily exerts its anti-inflammatory effect by inhibiting proinflammatory cytokines such as IL-1, IL-6, IL-12, and TNF as well as chemokines (34). IL-10 also inhibits antigen presentation by blocking MHC class II expression and co-stimulatory molecules such as CD80 and CD86 (35). IL-10 exerts its biological effect by binding to its receptor which is composed of two subunits, IL10R1 and IL-10R2 (35). Initially, IL-10 binds its cognate receptor IL-10R1 and the binding of IL-10R2 is specific to initiate a signaling cascade. IL-10 then activates Janus kinase (JAK) and STAT pathways. This recruits Tyk2 and Jak1 to the receptor complex and induces phosphorylation of the receptors leading to transcription of IL-10-regulated genes (36). IL-10 production is also associated with other types of immune cells such as macrophages and myeloid-derived suppressor cells (MDSCs). Following Tolllike receptor (TLR) activation in macrophages and MDSCs, the signaling cascade comprising the adaptor molecule TIR-domaincontaining adaptor protein inducing IFN $\beta$ (TRIF) is activated. The extracellular signal-regulated kinase 1 (ERK1), ERK2, p38, and nuclear factor- $\kappa \mathrm{B}(\mathrm{NF}-\kappa \mathrm{B})$ pathways are activated leading to the production of IL-10 and several other genes. IL-10 up-regulates its own production by modulating tumor progression locus 2 (TPL2) expression (34). Both IL-4 and IL-10 mediate signaling between immune cells and also regulate recruitment, activation, and suppression of both immune and non-immune cells.

\section{MODULATION OF IL-4 AND IL-10 DURING PREGNANCY}

Anti-inflammatory cytokines perform a multitude of functions during normal pregnancy by promoting placental formation, modulating trophoblast invasion and differentiation, inducing placental proliferation and angiogenesis, and inhibiting proinflammatory cytokines. IL-4 is detectable at the feto-maternal interface during all phases of pregnancy (37). IL-4 is produced not only by immune cells of the placenta but also by the maternal decidua, amniochorionic membranes, cytotrophoblasts, and both maternal and fetal endothelial cells $(38,39)$. IL-4 production is increased in the gravid state and levels of IL-4 increase throughout normal pregnancy (40). Progesterone is a known inducer of IL-4 and together they act to inhibit Th1 responses during pregnancy. Given the important role of IL-4 in suppressing inflammation, it is surprising that IL-4-knockout mice have normal pregnancies with respect to fetal growth and development (41). This would suggest that the role of an individual cytokine may not be crucial to the success of pregnancy but rather depends on the complex interplay with other cytokines in a spatiotemporal manner.

Interleukin-10 has been shown to be constitutively expressed in placental villous trophoblasts but not in extravillous trophoblasts (42). Additionally, uterine NK cells (uNK cells), monocytes, and Tregs in the decidua are also important producers of IL-10 (36). IL-10 acts on its receptors (IL-10R) that are expressed on several cell types including placental trophoblasts, decidual stromal cells, macrophages, and uNK cells. In mice, IL-10 is expressed throughout pregnancy and peaks at gestational day 12 (37). To determine the exact role of IL-10 in pregnancy, pregnant IL-10 $1-1-$ mice were compared to pregnant wild type (WT) mice and no change in litter size or development were noted indicating that IL-10 is not essential for pregnancy (41). However, IL-10 plays a role in placental growth and remodeling because IL- $10^{-1-}$ mice exhibited increases in placental size and maternal blood sinuses (43). IL-10 is not essential for the growth and development of the fetus in mice but rather it plays an important role to inhibit excessive inflammation. Pregnant IL-10 $10^{-/}$mice are susceptible to low doses of LPS and CpG (a TLR 9 agonist) compared to WT mice $(44,45)$. These results suggest that IL-10 acts as a protective agent during infection and deficiency of IL-10 exacerbates inflammation in mice. Normal pregnant women were determined to have increased IL-10 production during the first and second trimesters but not in the third trimester (46). Moreover, IL-10 production decreases prior to labor and delivery of the fetus and placenta and increases post labor (47). Precise regulation of IL- 4 and IL-10 are important to curtail maternal inflammation and allow crosstalk between the placental decidua and the invading fetal trophoblasts at different stages of pregnancy.

\section{IL-4 AND IL-10 IN SPONTANEOUS ABORTION AND FETAL GROWTH RESTRICTION}

It has been well documented that the lack of fetal tolerance is largely mediated by Th1 cells. Their recruitment from the maternal 
circulation into the feto-maternal interface and their production of pro-inflammatory cytokines coupled with a decrease or lack of increase in anti-inflammatory cytokines can lead to a spectrum of pregnancy disorders (Figure 1). Various cells that produce IL4 and IL-10 including NK cells, T cells, regulatory B cells, and others are dysregulated and fail to increase production of these anti-inflammatory cytokines at the appropriate time and location.

Immunological models of spontaneous abortion and FGR in animals include the female $\mathrm{CBA} / \mathrm{J} \times$ male DBA/2J mating with and without stress, excessive TLR activation in early pregnancy (LPS and poly I:C), and transvaginal rIL-17 administration, and all of these are associated with decreased production of IL-4 and IL-10. Several studies have reported that abortion-prone CBA/J females demonstrate decreased circulating and placental levels of IL- 4 and IL-10 $(18,48-52)$ and that experimental therapeutics at various time points including a B7 monoclonal antibody, adenoviralmediated heme oxygenase-1 overexpression, progesterone or its derivatives, adoptive transfer of Tregs, or alloimmunization, all decrease abortion rate and this is associated with increased IL-4 and IL-10 and/or Th2/Th1 ratios (18, 48-50, 52-55). A more direct study demonstrated that administration of IL- 4 as well as IL-4 and IL-10 decreased the resorption rate in these mice (51). In animals, TLR activation in early pregnancy induces spontaneous abortion or resorption and this is regulated by IL-10 as rIL-10 administration was able to prevent these effects (18, 56-59). Further support for IL-10 and its role in preventing spontaneous abortion was demonstrated in mice administered rIL-17 transvaginally on gestational day 1 which decreased decidual IL-10 levels and induced abortion (53). Adoptive transfer of IL-10-producing Tregs from pregnant mice increased IL-10 levels and decreased abortion rates in these mice (53).

These experimental studies are supported by clinical observations in women who have had recurrent or initial reproductive failures. Production of IL- 4 and IL-10 by NK cells, regulatory B cells, $\mathrm{T}$ cells, and others is decreased in women who have had spontaneous abortions, recurrent miscarriages, small for gestational age babies, and infertility. Several studies have reported low levels of IL-4, IL-4-producing cells, and Th1 cytokine/IL-4 ratios in women with spontaneous abortions (60-65). With respect to IL-10, numerous studies have reported low levels of IL-10, IL-10producing cells, and Th1 cytokine/IL-10 ratios in women with spontaneous abortions (40, 61-71). Additionally, women experiencing multiple unsuccessful in vitro fertilization cycles have increased TNF $\alpha+/ \mathrm{IL}-4+$ and $\mathrm{TNF} \alpha+/ \mathrm{IL}-10+\mathrm{T}$ cell ratios (65). A recent study found that low levels of circulating anti-inflammatory cytokines during early gestation were associated with habitual miscarriages in women (72). Further support for an important role of IL-4 and IL-10 in preventing reproductive failure was provided by a study in which i.v. Ig therapy in women with recurrent spontaneous abortions increased IL-4 and IL-10 levels and decreased the ratio of IFN $\gamma+/ \mathrm{IL}-4+\mathrm{T}$ cells (73). Together these data support the notion that a lack of early, appropriate anti-inflammatory responses and excessive inflammation can lead to reproductive failure. Further experimental and clinical studies in which augmentation of IL-4- and IL-10-producing immune cells would determine whether this would be sufficient to induce successful pregnancies.

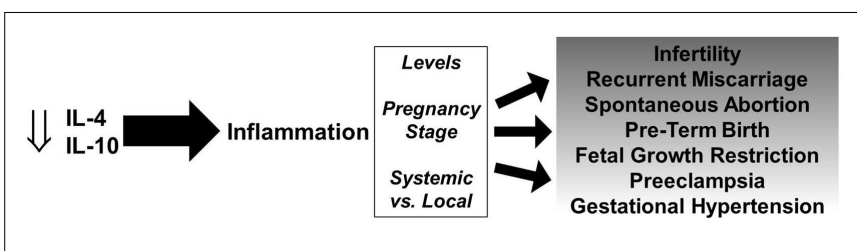

FIGURE 1 | Role of IL-4 and IL-10 in pregnancy disorders. Decreased levels of IL-4 and IL-10 promote persistent inflammation and depending on the levels, stage of pregnancy, and systemic vs. local effects, can lead to a spectrum of gestational complications.

\section{IL-4 AND IL-10 IN PREECLAMPSIA}

One of the characteristics and potential cause in some cases of PE is uncontrolled amplification of the maternal immune system. The excessive pro-inflammatory state seen in PE may be partly due to increased production of pro-inflammatory cytokines and/or decreased production of anti-inflammatory cytokines. Indeed, PE-like symptoms develop in rats following infusion of IL-6 or $\mathrm{TNF} \alpha$ indicating that pro-inflammatory cytokines contribute to the development of PE $(74,75)$. Recent experiments from our lab indicate a pathogenetic role of decreases in the anti-inflammatory cytokine IL-4 in PE. We demonstrated that although fetal growth and development was not affected in IL- $4^{-1-}$ mice, mild PE-like symptoms such as hypertension and proteinuria developed during pregnancy. Additionally, deficiency of IL-4 induced systemic and placental inflammation in mice. These experiments implicate that deficiency of IL-4 contributes to mild cardiovascular and renal effects and the protective role of IL-4 is more pronounced during infection. In support, we demonstrated that pregnant IL$4^{-l-}$ mice exhibited even further increases in inflammation and PE-like symptoms following viral mimetic activation of TLR3. Importantly, non-pregnant IL- $4^{-1-}$ mice did not exhibit hypertension and proteinuria at baseline or following TLR3 activation (76). These observations also correlate well with numerous clinical studies in which women with PE have been reported to have decreased IL-4 levels and increased circulating levels of the soluble IL-4 receptor compared with normotensive pregnant women (77-79). These studies establish a role for decreased IL-4 in the development of PE and also indicate that administration of IL-4 may be a viable treatment option for women with PE.

Similar to IL-4, several studies document the importance of IL-10 in preventing PE. Serum from PE patients induces the clinical features of PE such as hypertension, proteinuria, and FGR in IL- $10^{-/-}$mice. PE serum induced HIF- $1 \alpha$ in the placenta which may have triggered production of the anti-angiogenic factors sFlt1 and sEng and also induced renal pathology and poor spiral artery remodeling. Endovascular capillary tube formation is also significantly disrupted by serum from PE patients in these IL$10^{-/-}$mice. However, serum from healthy women or women with $\mathrm{PE}$ administered to non-pregnant animals failed to induce any PE-like features (80). In another study by Lai et al. deficiency of IL-10 coupled with hypoxia induced severe PE-like features including renal pathology, proteinuria, and hypertension. Moreover, increased expression of anti-angiogenic factors, apoptotic pathways, and placental injury were noted. Expectedly, recombinant IL-10 administration reversed the hypoxia-induced features 
in pregnant IL- $10^{-/-}$mice confirming the protective role of IL-10 in PE (81). In our studies, pregnant IL- $10^{-/-}$mice exhibit mild hypertension, endothelial dysfunction, and proteinuria only during pregnancy. In addition, PE-like symptoms were augmented in IL- $10^{-/-}$mice following activation of TLR3 during pregnancy (82). Clinical studies further support reduced production of IL-10 from patients with PE (83).

Based on the aforementioned studies, we hypothesized that administration of either of the anti-inflammatory cytokines IL4 or IL-10 or co-treatment with both recombinant IL-4 and IL-10 may improve outcomes in TLR-activated PE mice. Administration of IL-4, IL-10 alone, or IL-4/IL-10 co-treatment during gestation normalized blood pressure and endothelial function in mice treated with a TLR3 agonist. IL-4/IL-10 co-treatment had the most beneficial effect on fetal development and renal function as well as decreased the levels of the pro-inflammatory cytokines IL-6, IFN $\gamma$, and TNF $\alpha$ (84). These studies raise the possibility of using anti-inflammatory cytokines in combination as a therapeutic option for women with PE.

\section{CONCLUSION}

The role of inflammation is important and necessary for successful pregnancies, however aberrant and persistent inflammation and the lack of resolution by anti-inflammatory cytokine-producing cells can lead to a variety of pregnancy disorders depending on various factors (Figure 1). IL-4 and IL-10 play crucial roles in the success of pregnancy and there is strong evidence that a deficiency in IL-4 and/or IL-10 contributes to infertility, spontaneous abortion, PTB, FGR, and hypertensive disorders of pregnancy.

Most studies to date have aimed to determine the role of each individual cytokine which has generated important findings and improved our understanding of the role of anti-inflammatory mediators during pregnancy; however there is considerable redundancy among cytokines and within an immune response. Integrative studies that take into context the local environment and cytokine milieu, especially during the gravid state, are necessary to determine how cytokine-cell and cell-cell communication influences local and systemic inflammation and the physiological effects during pregnancy. Novel therapies that target the augmentation of multiple anti-inflammatory cytokines including both IL-4 and IL-10 may elicit better effects than a single antiinflammatory cytokine targeting therapy. The challenge will be in determining when, where, and how to achieve this during gestation in order to produce a healthy, successful pregnancy.

\section{REFERENCES}

1. Medawar PB. Immunity to homologous grafted skin; the fate of skin homografts transplanted to the brain, to subcutaneous tissue, and to the anterior chamber of the eye. Br J Exp Pathol (1948) 29(1):58-69.

2. Wegmann TG, Lin H, Guilbert L, Mosmann TR. Bidirectional cytokine interactions in the maternal-fetal relationship: is successful pregnancy a TH2 phenomenon? Immunol Today (1993) 14(7):353-6. doi:10.1016/0167-5699(93)90235-D

3. Burns WR, Wang Y, Tang PC, Ranjbaran H, Iakimov A, Kim J, et al. Recruitment of CXCR3 + and CCR5 + T cells and production of interferon-gamma-inducible chemokines in rejecting human arteries. Am J Transplant (2005) 5(6):1226-36. doi:10.1111/j.1600-6143.2005.00892.X

4. Erdmann AA, Jung U, Foley JE, Toda Y, Fowler DH. Co-stimulated/Tc2 cells abrogate murine marrow graft rejection. Biol Blood Marrow Transplant (2004) 10(9):604-13. doi:10.1016/j.bbmt.2004.06.006
5. Suthanthiran M, Strom TB. Immunobiology and immunopharmacology of organ allograft rejection. J Clin Immunol (1995) 15(4):161-71. doi:10.1007/ BF01541085

6. Li XC, Zand MS, Li Y, Zheng XX, Strom TB. On histocompatibility barriers, Th1 to Th2 immune deviation, and the nature of the allograft responses. J Immunol (1998) 161(5):2241-7.

7. Strom TB, Roy-Chaudhury P, Manfro R, Zheng XX, Nickerson PW, Wood K, et al. The Th1/Th2 paradigm and the allograft response. Curr Opin Immunol (1996) 8(5):688-93. doi:10.1016/S0952-7915(96)80087-2

8. Nickerson P, Steurer W, Steiger J, Zheng X, Steele AW, Strom TB. Cytokines and the Th1/Th2 paradigm in transplantation. Curr Opin Immunol (1994) 6(5):757-64. doi:10.1016/0952-7915(94)90081-7

9. Fredricks DN, Fiedler TL, Marrazzo JM. Molecular identification of bacteria associated with bacterial vaginosis. N Engl J Med (2005) 353(18):1899-911. doi:10.1056/NEJMoa043802

10. DiGiulio DB, Romero R, Amogan HP, Kusanovic JP, Bik EM, Gotsch F, et al. Microbial prevalence, diversity and abundance in amniotic fluid during preterm labor: a molecular and culture-based investigation. PLoS One (2008) 3(8):e3056. doi:10.1371/journal.pone.0003056

11. Menard JP, Mazouni C, Salem-Cherif I, Fenollar F, Raoult D, Boubli L, et al. High vaginal concentrations of Atopobium vaginae and Gardnerella vaginalis in women undergoing preterm labor. Obstet Gynecol (2010) 115(1):134-40. doi:10.1097/AOG.0b013e3181c391d7

12. Infante-Duarte C, Kamradt T. Th1/Th2 balance in infection. Springer Semin Immunopathol (1999) 21(3):317-38. doi:10.1007/BF00812260

13. Guleria I, Pollard JW. The trophoblast is a component of the innate immune system during pregnancy. Nat Med (2000) 6(5):589-93. doi:10.1038/75074

14. Kramer BW, Kallapur S, Newnham J, Jobe AH. Prenatal inflammation and lung development. Semin Fetal Neonatal Med (2009) 14(1):2-7. doi:10.1016/j.siny. 2008.08.011

15. Kunzmann S, Collins JJ, Kuypers E, Kramer BW. Thrown off balance: the effect of antenatal inflammation on the developing lung and immune system. Am J Obstet Gynecol (2013) 208(6):429-37. doi:10.1016/j.ajog.2013.01.008

16. Germain M, Krohn MA, Hillier SL, Eschenbach DA. Genital flora in pregnancy and its association with intrauterine growth retardation. J Clin Microbiol (1994) 32(9):2162-8.

17. Gendron RL, Nestel FP, Lapp WS, Baines MG. Lipopolysaccharide-induced fetal resorption in mice is associated with the intrauterine production of tumour necrosis factor-alpha. J Reprod Fertil (1990) 90(2):395-402. doi:10.1530/jrf.0. 0900395

18. Chaouat G, Assal Meliani A, Martal J, Raghupathy R, Elliott JF, Mosmann T, et al. IL-10 prevents naturally occurring fetal loss in the CBA x DBA/2 mating combination, and local defect in IL-10 production in this abortion-prone combination is corrected by in vivo injection of IFN-tau. J Immunol (1995) 154(9): 4261-8.

19. Rijhsinghani AG, Thompson K, Tygrette L, Bhatia SK. Inhibition of interleukin10 during pregnancy results in neonatal growth retardation. Am J Reprod Immunol (1997) 37(3):232-5. doi:10.1111/j.1600-0897.1997.tb00220.x

20. Zenclussen AC, Fest S, Joachim R, Klapp BF, Arck PC. Introducing a mouse model for pre-eclampsia: adoptive transfer of activated Th1 cells leads to preeclampsia-like symptoms exclusively in pregnant mice. Eur J Immunol (2004) 34(2):377-87. doi:10.1002/eji.200324469

21. Gregory GD, Raju SS, Winandy S, Brown MA. Mast cell IL-4 expression is regulated by Ikaros and influences encephalitogenic Th1 responses in EAE. J Clin Invest (2006) 116(5):1327-36. doi:10.1172/JCI27227

22. Min B, Prout M, Hu-Li J, Zhu J, Jankovic D, Morgan ES, et al. Basophils produce IL-4 and accumulate in tissues after infection with a Th2-inducing parasite. J Exp Med (2004) 200(4):507-17. doi:10.1084/jem.20040590

23. Le Gros G, Ben-Sasson SZ, Seder R, Finkelman FD, Paul WE. Generation of interleukin 4 (IL-4)-producing cells in vivo and in vitro: IL-2 and IL-4 are required for in vitro generation of IL-4-producing cells. J Exp Med (1990) 172(3):921-9. doi:10.1084/jem.172.3.921

24. Croft M, Swain SL. Recently activated naive CD4 T cells can help resting B cells, and can produce sufficient autocrine IL-4 to drive differentiation to secretion of T helper 2-type cytokines. J Immunol (1995) 154(9):4269-82.

25. Nelms K, Keegan AD, Zamorano J, Ryan JJ, Paul WE. The IL-4 receptor: signaling mechanisms and biologic functions. Annu Rev Immunol (1999) 17:701-38. doi:10.1146/annurev.immunol.17.1.701 
26. Shimoda K, van Deursen J, Sangster MY, Sarawar SR, Carson RT, Tripp RA, et al. Lack of IL-4-induced Th2 response and IgE class switching in mice with disrupted Stat6 gene. Nature (1996) 380(6575):630-3. doi:10.1038/380630a0

27. Takeda K, Tanaka T, Shi W, Matsumoto M, Minami M, Kashiwamura S, et al. Essential role of Stat6 in IL-4 signalling. Nature (1996) 380(6575):627-30. doi: $10.1038 / 380627 \mathrm{a} 0$

28. Ouyang W, Ranganath SH, Weindel K, Bhattacharya D, Murphy TL, Sha WC, et al. Inhibition of Th1 development mediated by GATA-3 through an IL-4independent mechanism. Immunity (1998) 9(5):745-55. doi:10.1016/S10747613(00)80671-8

29. Pillemer BB, Qi Z, Melgert B, Oriss TB, Ray P, Ray A. STAT6 activation confers upon $\mathrm{T}$ helper cells resistance to suppression by regulatory $\mathrm{T}$ cells. J Immunol (2009) 183(1):155-63. doi:10.4049/jimmunol.0803733

30. Skapenko A, Kalden JR, Lipsky PE, Schulze-Koops H. The IL-4 receptor alphachain-binding cytokines, IL-4 and IL-13, induce forkhead box P3-expressing CD25+CD4+ regulatory T cells from CD25-CD4+ precursors. Jimmunol (2005) 175(9):6107-16. doi:10.4049/jimmunol.175.9.6107

31. Wei J, Duramad O, Perng OA, Reiner SL, Liu YJ, Qin FX. Antagonistic nature of $\mathrm{T}$ helper $1 / 2$ developmental programs in opposing peripheral induction of Foxp3+ regulatory T cells. Proc Natl Acad Sci U S A (2007) 104(46):18169-74. doi:10.1073/pnas.0703642104

32. Bettelli E, Carrier Y, Gao W, Korn T, Strom TB, Oukka M, et al. Reciprocal developmental pathways for the generation of pathogenic effector TH17 and regulatory T cells. Nature (2006) 441(7090):235-8. doi:10.1038/nature04753

33. Fiorentino DF, Bond MW, Mosmann TR. Two types of mouse T helper cell. IV. Th2 clones secrete a factor that inhibits cytokine production by Th1 clones. J Exp Med (1989) 170(6):2081-95. doi:10.1084/jem.170.6.2081

34. Saraiva M, O'Garra A. The regulation of IL-10 production by immune cells. Nat Rev Immunol (2010) 10(3):170-81. doi:10.1038/nri2711

35. Moore KW, de Waal Malefyt R, Coffman RL, O'Garra A. Interleukin-10 and the interleukin-10 receptor. Annu Rev Immunol (2001) 19:683-765. doi:10.1146/ annurev.immunol.19.1.683

36. Thaxton JE, Sharma S. Interleukin-10: a multi-faceted agent of pregnancy. Am J Reprod Immunol (2010) 63(6):482-91. doi:10.1111/j.1600-0897.2010.00810.x

37. Lin H, Mosmann TR, Guilbert L, Tuntipopipat S, Wegmann TG. Synthesis of T helper 2-type cytokines at the maternal-fetal interface. J Immunol (1993) 151(9):4562-73

38. Jones CA, Finlay-Jones JJ, Hart PH. Type-1 and type-2 cytokines in human late-gestation decidual tissue. Biol Reprod (1997) 57(2):303-11. doi:10.1095/ biolreprod57.2.303

39. Chaouat G, Cayol V, Mairovitz V, Dubanchet S. Localization of the Th2 cytokines IL-3, IL-4, IL-10 at the fetomaternal interface during human and murine pregnancy and lack of requirement for Fas/Fas ligand interaction for a successful allogeneic pregnancy. Am J Reprod Immunol (1999) 42(1):1-13. doi:10.1111/j.1600-0897.1999.tb00459.x

40. Marzi M, Vigano A, Trabattoni D, Villa ML, Salvaggio A, Clerici E, et al. Characterization of type 1 and type 2 cytokine production profile in physiologic and pathologic human pregnancy. Clin Exp Immunol (1996) 106(1):127-33. doi:10.1046/j.1365-2249.1996.d01-809.x

41. Svensson L, Arvola M, Sallstrom MA, Holmdahl R, Mattsson R. The Th2 cytokines IL-4 and IL-10 are not crucial for the completion of allogeneic pregnancy in mice. J Reprod Immunol (2001) 51(1):3-7. doi:10.1016/S01650378(01)00065-1

42. Roth I, Corry DB, Locksley RM, Abrams JS, Litton MJ, Fisher SJ. Human placental cytotrophoblasts produce the immunosuppressive cytokine interleukin 10 . J Exp Med (1996) 184(2):539-48. doi:10.1084/jem.184.2.539

43. Roberts CT, White CA, Wiemer NG, Ramsay A, Robertson SA. Altered placental development in interleukin-10 null mutant mice. Placenta (2003) 24(Suppl A):S94-9. doi:10.1053/plac.2002.0949

44. Murphy SP, Fast LD, Hanna NN, Sharma S. Uterine NK cells mediate inflammation-induced fetal demise in IL-10-null mice. J Immunol (2005) 175(6):4084-90. doi:10.4049/jimmunol.175.6.4084

45. Thaxton JE, Romero R, Sharma S. TLR9 activation coupled to IL-10 deficiency induces adverse pregnancy outcomes. JImmunol (2009) 183(2):1144-54. doi:10.4049/jimmunol.0900788

46. Hanna N, Hanna I, Hleb M, Wagner E, Dougherty J, Balkundi D, et al. Gestational age-dependent expression of IL-10 and its receptor in human placental tissues and isolated cytotrophoblasts. J Immunol (2000) 164(11):5721-8. doi:10.4049/jimmunol.164.11.5721
47. Simpson KL, Keelan JA, Mitchell MD. Labor-associated changes in interleukin10 production and its regulation by immunomodulators in human choriodecidua. J Clin Endocrinol Metab (1998) 83(12):4332-7. doi:10.1210/ jcem.83.12.5335

48. Jin LP, Zhou YH, Zhu XY, Wang MY, Li DJ. Adoptive transfer of paternal antigen-hyporesponsive T cells facilitates a Th2 bias in peripheral lymphocytes and at materno-fetal interface in murine abortion-prone matings. Am J Reprod Immunol (2006) 56(4):258-66. doi:10.1111/j.1600-0897.2006. 00425.x

49. Zenclussen AC, Gerlof K, Zenclussen ML, Sollwedel A, Bertoja AZ, Ritter $\mathrm{T}$, et al. Abnormal T-cell reactivity against paternal antigens in spontaneous abortion: adoptive transfer of pregnancy-induced CD4+CD25+ T regulatory cells prevents fetal rejection in a murine abortion model. Am J Pathol (2005) 166(3):811-22. doi:10.1016/S0002-9440(10)62302-4

50. Yin Y, Han X, Shi Q, Zhao Y, He Y. Adoptive transfer of CD4+CD25+ regulatory $\mathrm{T}$ cells for prevention and treatment of spontaneous abortion. Eur J Obstet Gynecol Reprod Biol (2012) 161(2):177-81. doi:10.1016/j.ejogrb.2011. 12.023

51. Jiang PJ, Zhao AM, Bao SM, Xiao SJ, Xiong M. Expression of chemokine receptors CCR3, CCR5 and CXCR3 on CD4(+) T cells in CBA/JxDBA/2 mouse model, selectively induced by IL-4 and IL-10, regulates the embryo resorption rate. Chin Med J (Engl) (2009) 122(16):1917-21.

52. Zenclussen ML, Anegon I, Bertoja AZ, Chauveau C, Vogt K, Gerlof K, et al. Overexpression of heme oxygenase- 1 by adenoviral gene transfer improves pregnancy outcome in a murine model of abortion. J Reprod Immunol (2006) 69(1):35-52. doi:10.1016/j.jri.2005.10.001

53. Wang WJ, Liu FJ, Xin L, Hao CF, Bao HC, Qu QL, et al. Adoptive transfer of pregnancy-induced $\mathrm{CD} 4+\mathrm{CD} 25+$ regulatory $\mathrm{T}$ cells reverses the increase in abortion rate caused by interleukin 17 in the CBA/JxBALB/c mouse model. Hum Reprod (2014) 29(5):946-52. doi:10.1093/humrep/deu014

54. Joachim R, Zenclussen AC, Polgar B, Douglas AJ, Fest S, Knackstedt M, et al. The progesterone derivative dydrogesterone abrogates murine stress-triggered abortion by inducing a Th2 biased local immune response. Steroids (2003) 68(10-13):931-40. doi:10.1016/j.steroids.2003.08.010

55. Zenclussen AC, Sollwedel A, Bertoja AZ, Gerlof K, Zenclussen ML, Woiciechowsky $\mathrm{C}$, et al. Heme oxygenase as a therapeutic target in immunological pregnancy complications. Int Immunopharmacol (2005) 5(1):41-51. doi:10.1016/j.intimp.2004.09.011

56. Thaxton JE, Nevers T, Lippe EO, Blois SM, Saito S, Sharma S. NKG2D blockade inhibits poly(I:C)-triggered fetal loss in wild type but not in IL-10-/- mice. J Immunol (2013) 190(7):3639-47. doi:10.4049/jimmunol.1203488

57. Lin Y, Liang Z, Chen Y, Zeng Y. TLR3-involved modulation of pregnancy tolerance in double-stranded RNA-stimulated NOD/SCID mice. J Immunol (2006) 176(7):4147-54. doi:10.4049/jimmunol.176.7.4147

58. Renaud SJ, Cotechini T, Quirt JS, Macdonald-Goodfellow SK, Othman M, Graham CH. Spontaneous pregnancy loss mediated by abnormal maternal inflammation in rats is linked to deficient uteroplacental perfusion. J Immunol (2011) 186(3):1799-808. doi:10.4049/jimmunol.1002679

59. Robertson SA, Care AS, Skinner RJ. Interleukin 10 regulates inflammatory cytokine synthesis to protect against lipopolysaccharide-induced abortion and fetal growth restriction in mice. Biol Reprod (2007) 76(5):738-48. doi:10.1095/ biolreprod.106.056143

60. Xiao Y, Kong XB, Chen JY, Ruan Y. [Relationship between recurrent spontaneous abortion and the level of interferon-gamma and interleukin-4 in peripheral blood and gingival crevicular fluid of patients with chronic periodontitis]. Zhonghua Kou Qiang Yi Xue Za Zhi (2013) 48(3):150-4.

61. Jin LP, Fan DX, Zhang T, Guo PF, Li DJ. The costimulatory signal upregulation is associated with Thl bias at the maternal-fetal interface in human miscarriage. Am J Reprod Immunol (2011) 66(4):270-8. doi:10.1111/j.1600-0897.2011. 00997.x

62. Hanzlikova J, Ulcova-Gallova Z, Malkusova I, Sefrna F, Panzner P. TH1-TH2 response and the atopy risk in patients with reproduction failure. Am J Reprod Immunol (2009) 61(3):213-20. doi:10.1111/j.1600-0897.2009.00683.X

63. Piccinni MP, Beloni L, Livi C, Maggi E, Scarselli G, Romagnani S. Defective production of both leukemia inhibitory factor and type 2 T-helper cytokines by decidual $\mathrm{T}$ cells in unexplained recurrent abortions. Nat Med (1998) 4(9):1020-4. doi:10.1038/2006

64. Fukui A, Kwak-Kim J, Ntrivalas E, Gilman-Sachs A, Lee SK, Beaman K. Intracellular cytokine expression of peripheral blood natural killer cell subsets in 
women with recurrent spontaneous abortions and implantation failures. Fertil Steril (2008) 89(1):157-65. doi:10.1016/j.fertnstert.2007.02.012

65. Kwak-Kim JY, Chung-Bang HS, Ng SC, Ntrivalas EI, Mangubat CP, Beaman $\mathrm{KD}$, et al. Increased $\mathrm{T}$ helper 1 cytokine responses by circulating $\mathrm{T}$ cells are present in women with recurrent pregnancy losses and in infertile women with multiple implantation failures after IVF. Hum Reprod (2003) 18(4):767-73. doi:10.1093/humrep/deg156

66. Hossein H, Mahroo M, Abbas A, Firouzeh A, Nadia H. Cytokine production by peripheral blood mononuclear cells in recurrent miscarriage. Cytokine (2004) 28(2):83-6. doi:10.1016/j.cyto.2004.07.002

67. Rolle L, Memarzadeh Tehran M, Morell-Garcia A, Raeva Y, Schumacher A, Hartig R, et al. Cutting edge: IL-10-producing regulatory B cells in early human pregnancy. Am J Reprod Immunol (2013) 70(6):448-53. doi:10.1111/aji.12157

68. Wang WJ, Hao CF, Lin QD. Dysregulation of macrophage activation by decidual regulatory $\mathrm{T}$ cells in unexplained recurrent miscarriage patients. J Reprod Immunol (2011) 92(1-2):97-102. doi:10.1016/j.jri.2011.08.004

69. Hadinedoushan H, Mirahmadian M, Aflatounian A. Increased natural killer cell cytotoxicity and IL-2 production in recurrent spontaneous abortion. Am J Reprod Immunol (2007) 58(5):409-14. doi:10.1111/j.1600-0897.2007.00524.x

70. Raghupathy R, Makhseed M, Azizieh F, Hassan N, Al-Azemi M, Al-Shamali E. Maternal Th1- and Th2-type reactivity to placental antigens in normal human pregnancy and unexplained recurrent spontaneous abortions. Cell Immunol (1999) 196(2):122-30. doi:10.1006/cimm.1999.1532

71. Makhseed M, Raghupathy R, Azizieh F, Farhat R, Hassan N, Bandar A. Circulating cytokines and CD30 in normal human pregnancy and recurrent spontaneous abortions. Hum Reprod (2000) 15(9):2011-7. doi:10.1093/humrep/15.9.2011

72. Ziganshina MM, Krechetova LV, Vanko LV, Nikolaeva MA, Khodzhaeva ZS, Sukhikh GT. Time course of the cytokine profiles during the early period of normal pregnancy and in patients with a history of habitual miscarriage. Bull Exp Biol Med (2013) 154(3):385-7. doi:10.1007/s10517-013-1956-0

73. Yamada H, Morikawa M, Furuta I, Kato EH, Shimada S, Iwabuchi K, et al. Intravenous immunoglobulin treatment in women with recurrent abortions: increased cytokine levels and reduced $\mathrm{Th} 1 / \mathrm{Th} 2$ lymphocyte ratio in peripheral blood. Am J Reprod Immunol (2003) 49(2):84-9. doi:10.1034/j.1600-0897.2003. 01184.x

74. LaMarca BB, Bennett WA, Alexander BT, Cockrell K, Granger JP. Hypertension produced by reductions in uterine perfusion in the pregnant rat: role of tumor necrosis factor-alpha. Hypertension (2005) 46(4):1022-5. doi:10.1161/01.HYP. 0000175476.26719 .36

75. Lamarca B, Speed J, Ray LF, Cockrell K, Wallukat G, Dechend R, et al. Hypertension in response to IL-6 during pregnancy: role of AT1-receptor activation. Int J Interferon Cytokine Mediator Res (2011) 2011(3):65-70. doi:10.2147/IJICMR. S22329

76. Chatterjee P, Kopriva SE, Chiasson VL, Young KJ, Tobin RP, Newell-Rogers K, et al. Interleukin-4 deficiency induces mild preeclampsia in mice. J Hypertens (2013) 31(7):1414-23; discussion 23. doi:10.1097/HJH.0b013e328360ae6c
77. Saito S, Sakai M, SasakiY, Tanebe K, Tsuda H, Michimata T. Quantitative analysis of peripheral blood Th0, Th1, Th2 and the Th1:Th2 cell ratio during normal human pregnancy and preeclampsia. Clin Exp Immunol (1999) 117(3):550-5. doi:10.1046/j.1365-2249.1999.00997.x

78. Arriaga-Pizano L, Jimenez-Zamudio L, Vadillo-Ortega F, Martinez-Flores A, Herrerias-Canedo T, Hernandez-Guerrero C. The predominant Th1 cytokine profile in maternal plasma of preeclamptic women is not reflected in the choriodecidual and fetal compartments. J Soc Gynecol Investig (2005) 12(5):335-42. doi:10.1016/j.jsgi.2005.02.005

79. Jonsson Y, Ruber M, Matthiesen L, Berg G, Nieminen K, Sharma S, et al. Cytokine mapping of sera from women with preeclampsia and normal pregnancies. J Reprod Immunol (2006) 70(1-2):83-91. doi:10.1016/j.jri.2005.10.007

80. Kalkunte S, Boij R, Norris W, Friedman J, Lai Z, Kurtis J, et al. Sera from preeclampsia patients elicit symptoms of human disease in mice and provide a basis for an in vitro predictive assay. Am J Pathol (2010) 177(5):2387-98. doi:10.2353/ajpath.2010.100475

81. Lai Z, Kalkunte S, Sharma S. A critical role of interleukin-10 in modulating hypoxia-induced preeclampsia-like disease in mice. Hypertension (2011) 57(3):505-14. doi:10.1161/HYPERTENSIONAHA.110.163329

82. Chatterjee P, Chiasson VL, Kopriva SE, Young KJ, Chatterjee V, Jones KA, et al. Interleukin 10 deficiency exacerbates toll-like receptor 3-induced preeclampsialike symptoms in mice. Hypertension (2011) 58(3):489-96. doi:10.1161/ HYPERTENSIONAHA.111.172114

83. Hennessy A, Pilmore HL, Simmons LA, Painter DM. A deficiency of placental IL-10 in preeclampsia. J Immunol (1999) 163(6):3491-5.

84. Chatterjee P, Chiasson VL, Seerangan G, Tobin RP, Kopriva SE, Newell-Rogers $\mathrm{MK}$, et al. Combined treatment with IL-4 and IL-10 modulates immune cells and prevents hypertension in pregnant mice. Am J Hypertens (2014). doi:10.1093/ajh/hpu100

Conflict of Interest Statement: Our work on IL-4 and IL-10 was funded by American Heart Association Grant in Aid 4480033.

Received: 01 April 2014; paper pending published: 28 April 2014; accepted: 14 May 2014; published online: 27 May 2014.

Citation: Chatterjee P, Chiasson VL, Bounds KR and Mitchell BM (2014) Regulation of the anti-inflammatory cytokines interleukin-4 and interleukin-10 during pregnancy. Front. Immunol. 5:253. doi: 10.3389/fimmu.2014.00253

This article was submitted to Inflammation, a section of the journal Frontiers in Immunology.

Copyright (c) 2014 Chatterjee, Chiasson, Bounds and Mitchell. This is an open-access article distributed under the terms of the Creative Commons Attribution License (CC $B Y)$. The use, distribution or reproduction in other forums is permitted, provided the original author(s) or licensor are credited and that the original publication in this journal is cited, in accordance with accepted academic practice. No use, distribution or reproduction is permitted which does not comply with these terms. 